\title{
STUDYING THE FEASIBLTY OF TOTAL STATION \\ IN ARCHITECTRAL SURVEY AS COMPARE TO THE \\ CONVENTIONAL CLOSE-RANGE \\ PHOTOGRAMMETRIC TECHNIQUE
}

\author{
Abo El- Hassan M.Rahil
}

\begin{abstract}
In this work, the total station survey and the analytical photogrammetry, were uesd in architectural photogrammetry.In this study, a test site was used for the comparison between the total station survey and the analytical photogrammtry and for experimental determination of the accuracy of the total station survey. Two facades from the test site were photographed with a metric camera, using single and convergent photographs. The accuracy of both the close range photogrammetry and the total station techniques in architectural surves was detrmined by, comparing the obtained coordinates with the original check points coordinates of the test site. The results indicated that, the total station technique results are conform with the correspond close range photogrammetric results, but more economic and simple to applied

KEY WORD : Architectural photogrammetry; analytical photogrammetry; total station.

\section{INTRODUCTION}

There are many of the ancient Pharonic, Coptic, Roman and Islamic monuments in Egypt, which have a great importance for the whole world and at the same time, play an essential role in attracting tourists from other different parts of the world. Most of the monument in Egypt need to be restored, as the case of Al Fatimid - Cairo. For the purpose of the restoration, the monument should retain its original shape, otherwise, it would los its monuments value. One of the most convenient methods, which is used for the registration purposes, is the Close-Range Photogrammetry (analog, analytical and digital photogrammetry). Despite of the advantages of the Close- Range Photogrammetry, its use in Egypt is quite limited, because it needs, special experience, instruments, budget and great effort to regestrae the monuments.
\end{abstract}

Manuscript received from Dr. ABO EL-HASSAN M. RAHIL on : $21 / 3 / 2000$

Accepted on : 28/3/2000

Engineering Research Bulletin, Vol 23,No 2, 2000 Minufiya University, Faculty of Engineering, Shebien El-Kom , Egypt, ISSN 1110-1180 
For all of these reasons, the aim of this study, is to find a reliable, simple, rapid,convenient and economic technique, which can be used for the purpose of the regisration of building exteriors (facades) in geometrical terms

\section{The aims of this study are:}

-Studying the capability of the total station in architectural survey;

-Determining the group (According to the ICOMOS, there are three principal groups) of architectural survey, which can be achieved using the total station survey;

-Using the analytical photogrammetry in architectural photogrammetry; and -A comparative study between the obtained results from the analytical photogrammetry, as a conventional method, and the total station survey.

\section{BACKGROUND}

According to the ICOMOS (International Council of Monuments and Sites ) symposium in 1968, the architectural photogrammetry has been classified into three principal groups: rapid and relatively simple architectural photogrammetry surveys; precise surveys and very precise surveys Karara[89].

Rapid and relatively simple architectural photogrammetry surveys : Surveys of this type are used in preliminary studies for restoration or development, in inventory work, in the study of the history of art, and in other situations. An accuracy on the order of $5 \mathrm{~cm}$ (Karara [89 ]) is often considerd sufficient plotting is generally at scales of $1: 100$ or $1: 200$.

Precise surveys :

This second group of architectural photogrammetry surveys corresponds to the more general requirements of architects or art historians and is undertaken in the framework of surveys programs of conservation of heritage conucted by official organizations. Plotting is generally at a scale of $1: 50$ and the accuracy called for is 1 or $2 \mathrm{~cm}$ (Karara [89])

Very precise surveys :

Projects belonging to this third group are currently much fewer in number than projects belonging to either of the two previously discussed groups, particulary the second. The desired accuracy in this group is of $1 \mathrm{~mm}$ and in some cases of $0.1 \mathrm{~mm}$ (Karara [89])

\section{THE TEST SITE}

To study, the capability of the total station of solving problem of architectural photogrammetry, the palace of EL GAZAR BASHA was used as a test site. The palace of EL GAZAR BASHA is situated in the center of the Menoufiya University and was erected as the first distinguished secular building in Shebin El-Kom in the year 1920. Because of its location ( optimum conditions for observations, no public transport area ) it is particularly suited for testing the total station. The building has an rectangular- shaped ground plan and covers an area of about $35 \times 50 \mathrm{~m}$, and its height is about $12 \mathrm{~m}$ 


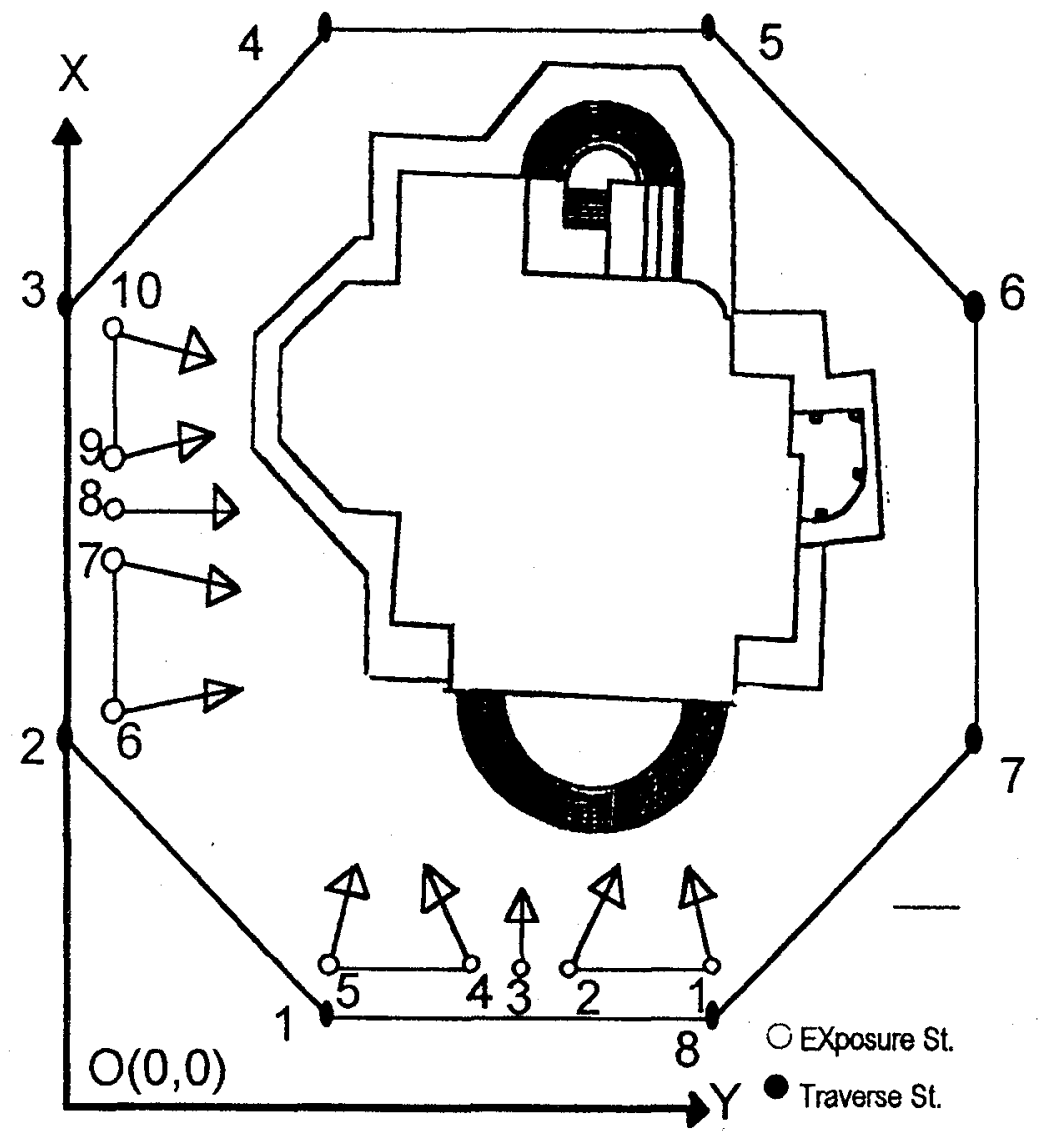

FIG.1 The local coordinate system and Photographic recording set-up

\section{DETERMINATION OF THE TARGET COORDINATES}

In this study, three different geodetic measurements had been carried out, which are:

Control point coordinates, check point coordinates and the total station observations $\left(\mathrm{X}_{\mathrm{I}}, \mathrm{Y}_{\mathrm{I}}\right.$ and $\left.\mathrm{Z}_{\mathrm{I}}\right)$. As a basis of the geodetic determination of the control point coordinates, the check point coordinates and the total station observations in a uniform object system, a closed traverse around the building was established. The traverse side $2-3$ is parallel to the respective east facade of the building, which corresponds to the $\mathrm{X}$-axis of the local coordinate system (Fig.1) . The traverse angles were measured in one set using one second theodolite ( Theo-10- A ) from Jena. At the same time, the horizontal and vertical angles to the control and check points, were measured at the points 1,8 and 2,3 of the traverse. The distance measurements of the traverse sides were taken twice using the subtance bar. The height of the traverse points were measured in a levelling loop by means of the Ni-07 from Jena,with the specifications of the precise levelling. On the basis of the calculated traverse point coordinates, the coordinates of the control and check points were subsequently determined by a personal computer IBM with the aid of the program "Space intersection". The program prepared by the auther, is used to determine the ground point coordinates, using the horizontal and vertical angles, 
the three object coordinates $\left(\mathrm{X}_{\mathrm{I}}, \mathrm{Y}_{\mathrm{I}}\right.$ and $\left.\mathrm{Z}_{\mathrm{I}}\right)$, and the residual errors in $\mathrm{Z}$ direction. The coordinates of all check points of the test site and the residual errors were calculatede and listed in table (1). Corresponding to the given instrument accuracies and the measurement results, the following mean square errors of points were obtained:

-for traverse points $\mathrm{mp}= \pm 5 \mathrm{~mm}$

- for control points $\mathrm{mp}= \pm 2 \mathrm{~mm}$

- for check points $\mathrm{mp}= \pm 2 \mathrm{~mm}$

\section{TABLE 1. THE COORDINATES OF THE CHECK POINTS}

\begin{tabular}{|c|c|c|c|c|c|c|}
\hline NO & $\mathbf{X}(\mathbf{m})$ & $Y(m)$ & $\mathbf{Z 1}(\mathbf{m})$ & $\mathrm{Z2}(\mathrm{m})$ & $\mathbf{Z}$ (mean) & $\mathrm{Z}$ diference \\
\hline 1 & 9.8302 & 14.8712 & 12.1377 & 12.1422 & 12.1399 & 0.00225 \\
\hline 2 & 4.8144 & 13.8151 & 11.3541 & 11.3580 & 11.3560 & 0.00195 \\
\hline 3 & 9.8620 & 14.8148 & 12.2110 & 12.2158 & 12.2134 & 0.0024 \\
\hline 4 & 3.2214 & 13.5505 & 11.1589 & 11.1622 & 11.1605 & 0.00165 \\
\hline 5 & 6.8230 & 15.7627 & 12.2397 & 12.2445 & 12.2421 & 0.0024 \\
\hline 6 & 7.8357 & 12.0122 & 14.6283 & 14.6316 & 14.6299 & 0.00165 \\
\hline 7 & 3.6244 & 13.7053 & 9.7381 & 9.7429 & 9.7405 & 0.0024 \\
\hline 8 & 7.8358 & 12.0199 & 1.0897 & 1.0958 & 1.09275 & 0.00305 \\
\hline 9 & 6.3412 & 21.5041 & 1.2198 & 1.2246 & 1.2222 & 0.0024 \\
\hline 10 & 5.2546 & 13.9510 & 14.0407 & 14.0455 & 14.0431 & 0.0024 \\
\hline 11 & 5.4327 & 14.1184 & 13.6162 & 13.6201 & 13.6181 & 0.00195 \\
\hline 12 & 5.4323 & 14.1200 & 11.4168 & 11.4201 & 11.4185 & 0.00165 \\
\hline 13 & 9.7563 & 12.4546 & 14.7422 & 14.7465 & 14.7443 & 0.00215 \\
\hline 14 & 6.6804 & 15.2203 & 15.4711 & 15.4754 & 15.4732 & 0.00242 \\
\hline 15 & 4.8144 & 13.8151 & 11.3541 & 11.3578 & 11.3555 & 0.00242 \\
\hline 16 & 2.7123 & 11.0642 & 6.2857 & 6.2890 & 6.2870 & 0.0013 \\
\hline 17 & 2.7147 & 11.2440 & 5.4244 & 5.4286 & 5.4265 & 0.0021 \\
\hline 18 & 2.2923 & 10.9438 & 1.0888 & 1.0929 & 1.09085 & 0.00205 \\
\hline 19 & 2.2962 & 10.9626 & 1.0325 & 1.03425 & 1.03425 & 0.00175 \\
\hline 20 & 7.4190 & 15.6438 & 12.1385 & 12.1436 & 12.1410 & 0.00255 \\
\hline 21 & 5.2716 & 10.6848 & 1.0988 & 1.1023 & 1.10055 & 0.00175 \\
\hline 22 & 14.6129 & 13.2907 & 10.5317 & 10.5360 & 10.5338 & 0.00215 \\
\hline 23 & 12.3767 & 14.0799 & 8.8517 & 8.8570 & 8.85435 & 0.00265 \\
\hline 24 & 14.5438 & 13.3957 & 2.5048 & 2.5097 & 2.50725 & 0.00245 \\
\hline 25 & 10.6014 & 14.5114 & 0.4604 & 0.4645 & 0.46245 & 0.00205 \\
\hline 26 & 14.5434 & 13.3956 & 2.5048 & 2.5083 & 2.50815 & 0.00335 \\
\hline 27 & 10.6264 & 14.3824 & 13.7468 & 13.7497 & 13.7482 & 0.00145 \\
\hline 28 & 10.7032 & 14.4813 & 13.7439 & 13.7462 & 13.7450 & 0.00115 \\
\hline 29 & 10.5599 & 14.6408 & 11.3286 & 11.3321 & 11.3303 & 0.00175 \\
\hline 30 & 4.0743 & 13.9966 & 14.9000 & 14.9039 & 14.9019 & 0.00195 \\
\hline 31 & 13.3949 & 15.8912 & 2.7996 & 2.8038 & 2.80160 & 0.0022 \\
\hline 32 & 5.4328 & 14.1496 & 9.7295 & 9.7328 & 9.73075 & 0.00125 \\
\hline 33 & 3.2395 & 13.6319 & 15.4023 & 15.4056 & 15.4039 & 0.00165 \\
\hline 34 & 3.3778 & 13.6439 & 14.0432 & 14.0483 & 14.0457 & 0.00255 \\
\hline 35 & 13.3949 & 15.8912 & 2.7996 & 2.8038 & 2.80160 & 0.0022 \\
\hline 36 & 4.0743 & 13.9966 & 14.9000 & 14.9039 & 14.9019 & 0.00195 \\
\hline 37 & $4: 6879$ & 13.8882 & 13.8209 & 13.8242 & 13.8225 & 0.00165 \\
\hline 38 & 7.1745 & 15.7202 & 11.3288 & 11.3351 & 12.6633 & 0.0016 \\
\hline 39 & 6.7939 & 15.6936 & 12.6617 & 12.6649 & 12.6633 & 0.0016 \\
\hline 40 & 9.6428 & 14.8068 & 13.8435 & 13.8496 & 13.8465 & 0.00305 \\
\hline 41 & 9.6445 & 14.8054 & 13.7417 & 13.745 & 13.7433 & 0.00165 \\
\hline 42 & 10.4456 & 14.5597 & 12.2811 & 12.2854 & 12.2832 & 0.00225 \\
\hline
\end{tabular}




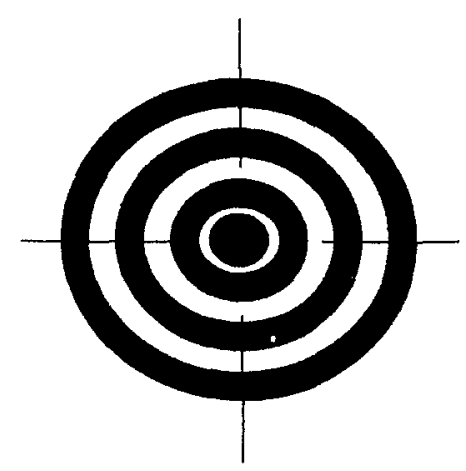

FIG. 2 The Taraget

\section{PHOTOGRAMMETRIC SURVEY; MEASUREMENTS AND CALCULATIONS}

Prior to measuring and taking photographs, all control points were marked and glued by targets ( black - and white circular shaped targets (Fig. 2 ) in order to ensure a good measuring conditions. The control points were chosen such that at least 12 points were optimally distributed on two facades of EL GAZAR BASHA's palace (north and east facade). In accordance with the local conditions, about 24 targets were glued to north and east facades of the object. The check points consists of 42 targets ( 20 fixed black- and white circular- shaped targets (Fig. 2 ), and 22 natural and good identified targets). The check points are equaly distributed on the two facades of the test site.

\section{Mathematical model}

The mathematical model for the terrestrial photogrammetric triangulations in this work is based on The Collinearity equation using the bundle method.

\section{COLLINEARITY EQUATION}

The Collinearity equation is the mathematical representation of the transformation of a terrain point $\mathrm{A}(\mathrm{X}, \mathrm{Y}, \mathrm{Z})$ to the corresponding image point a $(x, z)$, by a central perspective projection $O\left(X_{0}, Y_{0}, Z_{0}\right)$, and the rotation angles $\omega, \varphi, \kappa$ which are the parameters of exterior orientation. The inner orientation is defined by the focal length $\mathrm{C}$ and the position of the principale point $\mathrm{p}$ that is :

$$
x=-C \frac{m_{11}\left(X-X_{0}\right)+m_{21}\left(Y-Y_{0}\right)+m_{31}\left(Z-Z_{0}\right)}{m_{13}\left(X-X_{0}\right)+m_{23}\left(Y-Y_{0}\right)+m_{33}\left(Z-Z_{0}\right)}
$$




$$
z=-C \frac{m_{12}\left(X-X_{0}\right)+m_{22}\left(Y-Y_{0}\right)+m_{32}\left(Z-Z_{0}\right)}{m_{13}\left(X-X_{0}\right)+m_{23}\left(Y-Y_{0}\right)+m_{33}\left(Z-Z_{0}\right)}
$$

Where: $\mathrm{C}:$ is the camera constant ;

$\mathrm{x}, \mathrm{z}:$ are the image coordinates;

$\mathrm{X}, \mathrm{Y}, \mathrm{Z}$ : are the object space coordinates ;

$X_{0}, Y_{0}, Z_{0}$ : is the exposure station coordinate and;

$m_{11}$ to $m_{33}$ : are the elements of a matrix which is determined by

the rotation parameters $\omega, \varphi$ and $\kappa$.

The unknown parameters can be computed by bundle adjustment. For this purpose, control points must be measured in the ground reference system, on one hand, and in the image coordinate system, on the other. All photographs were taken with the metric camera UMK 10/1318 from Zeiss Jena. The north and east facades of the palace of EL-GAZAR BASHA were recorded as a case study. The positions of the stereomodels and single photographs as well as the camera directions are shown in Figure (1).All photographs were taken from the ground. The photographs were measured on the Technochart-D from Jena. In order to increase the accuracy, double measurements are recommended for photos. In any case, the photo measurement accuracy is $\pm 5 \mu \mathrm{m}$. Ten exposure stations were established, eight in a convergent imaging configuration and two single photographs. The bases of the altogether 4 stereo pairs were so arranged that they were approximately parallel to the respective facades. The elevation view of the north and east facade of EL GAZAR BASHA's palace are shown in Figure (4) and (5).

\section{TOTAL STATION SURVEYS AND MEASUREMENTS}

\section{PRACTICAL ASPECT}

The idea of using the total station survey in architectural photogrammetry, based on the Meydenbauer method in architectural photogrammetry, this means that the total station survey can be carried out point - by point to get the coordinates of all points, which represent the object ( measured drawing ).In this study all total station observations were taken with the total station SET 3C from SOKIA. Reffered to the coordinate system of the closed traverse (Fig. 1), the total station has been employed to determine the coordinates $\left(X_{1}, Y_{1}\right.$ and $\left.Z_{I}\right)$ of the necessary object points, which would be used to represent the two facades. In this work, a single reflector and a target sheet were used . In case of the height $(Z)$ of certain objects, where the reflecting prism or the taraget sheet cannot usually be positioned, the remote elevation measurement function has been used to calculate the height above the ground using a point directly above or below the object. 


\section{Measuring openings}

In this work, there are three different window openings which are to be measured. The one shown in Fig. (3.a) will present little difficulty, where points $a, b, c$ and $d$ are to be measured. The circular- headed openings shown in Fig.(3.b), there is no problems to determine the coordinate of points e, and $f$. The difficulty is to measure the curve, therefore the actual position of the points g, $h$ must be firstly determined using the cross-hair of the total station, which must be tangent to the start point and the end point of the curve, and finally the coordinates of the three points $\mathrm{g}, \mathrm{h}$ and $\mathrm{I}$ which lies on the curve must be measured. The same manner must be used for the opening, which has a segmental head Fig.(3.c).

\section{COMPUTER GRAPHICS}

The processed object space coordinates are then featured-coded with Auto CAD primetive commands: lines, B-spline, points, circles, layers, arcs, etc in an ASCII file. This code file, which is created interactively after the object space has been computed (in Analytical photogrammetry) or observed (in total station), is then routed to Auto CAD for automatic drafting. An example of the computer graphic with Auto CAD is shown in Fig.(6) and Fig.(7).

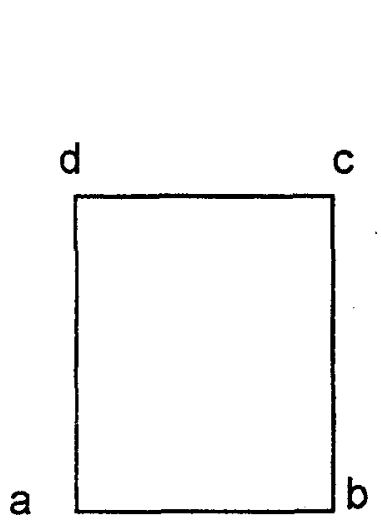

[Fig.3a] Rectangular

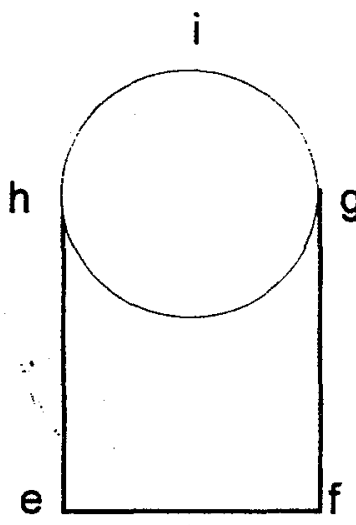

[Fig.3b]

Circular-head

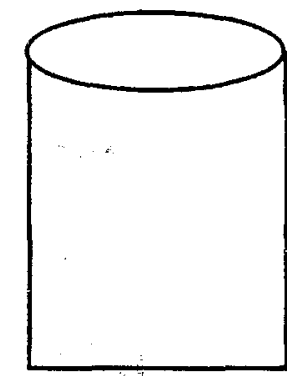

[Fig.3c]

Segmental-head

FIG. 3 Three simple window openings 


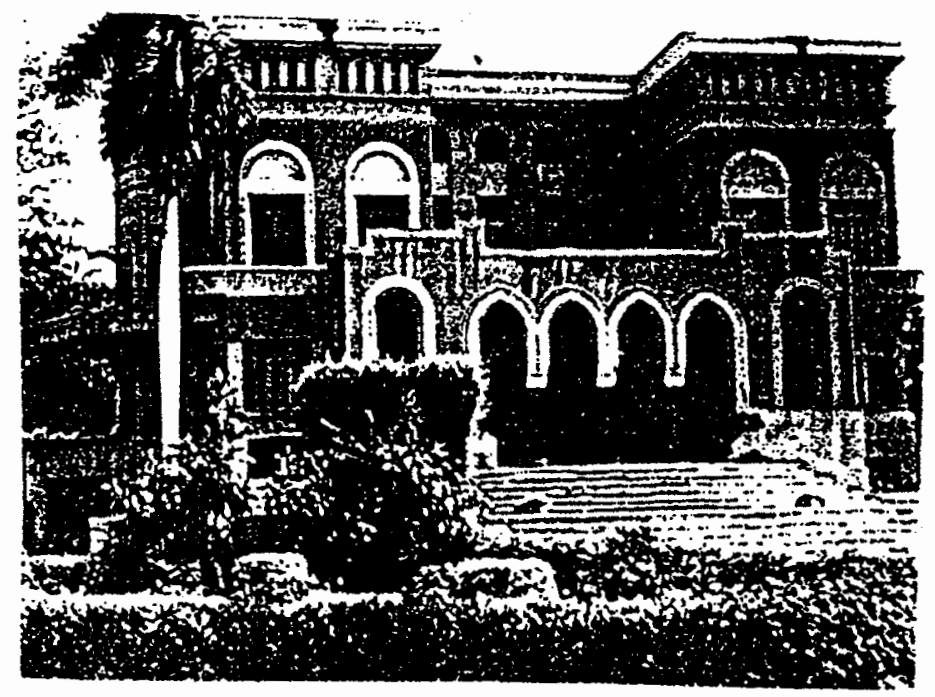

FIG.4 Photograph for the north facade of EL-GAZAR BASHA palace taken with UMK $10 / 1318$

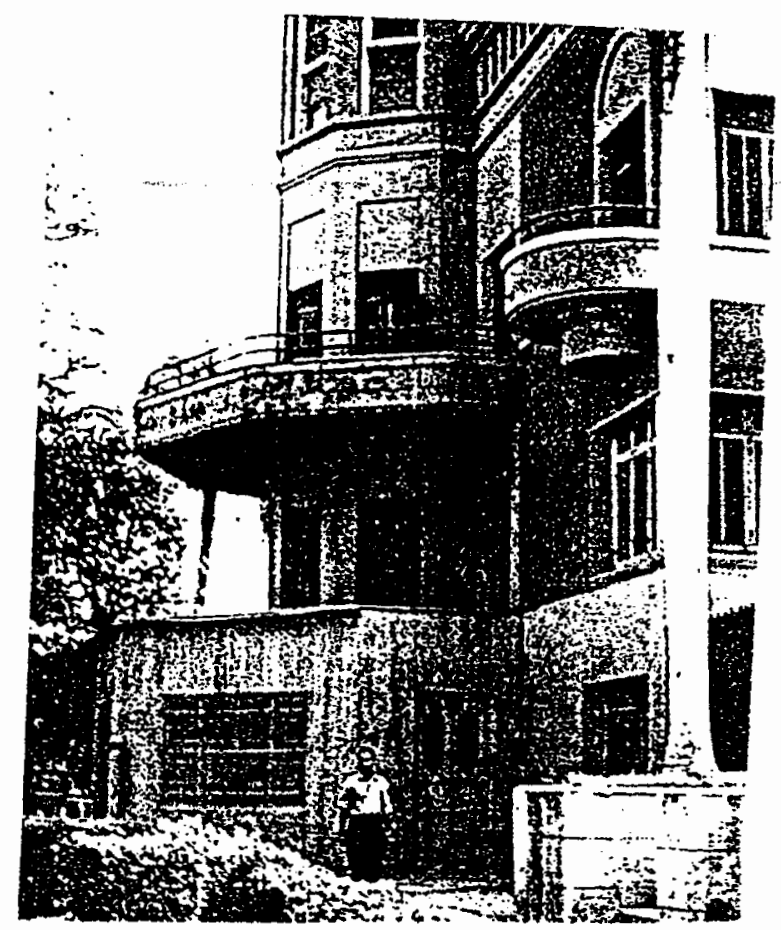

FIG.5 Photograph for the east facade of EL-GAZAR BASHA palace taken with UMK 10/1318 


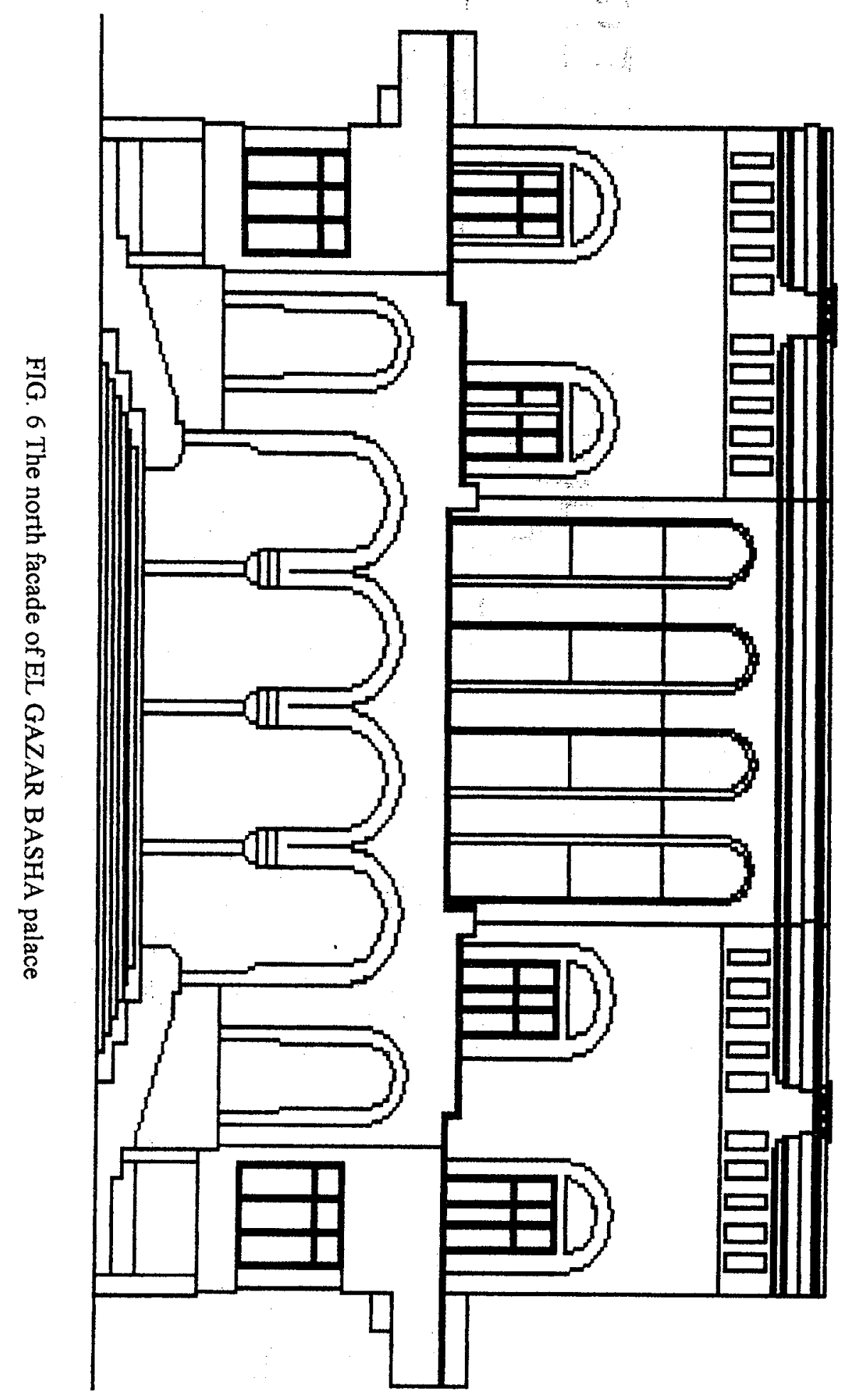




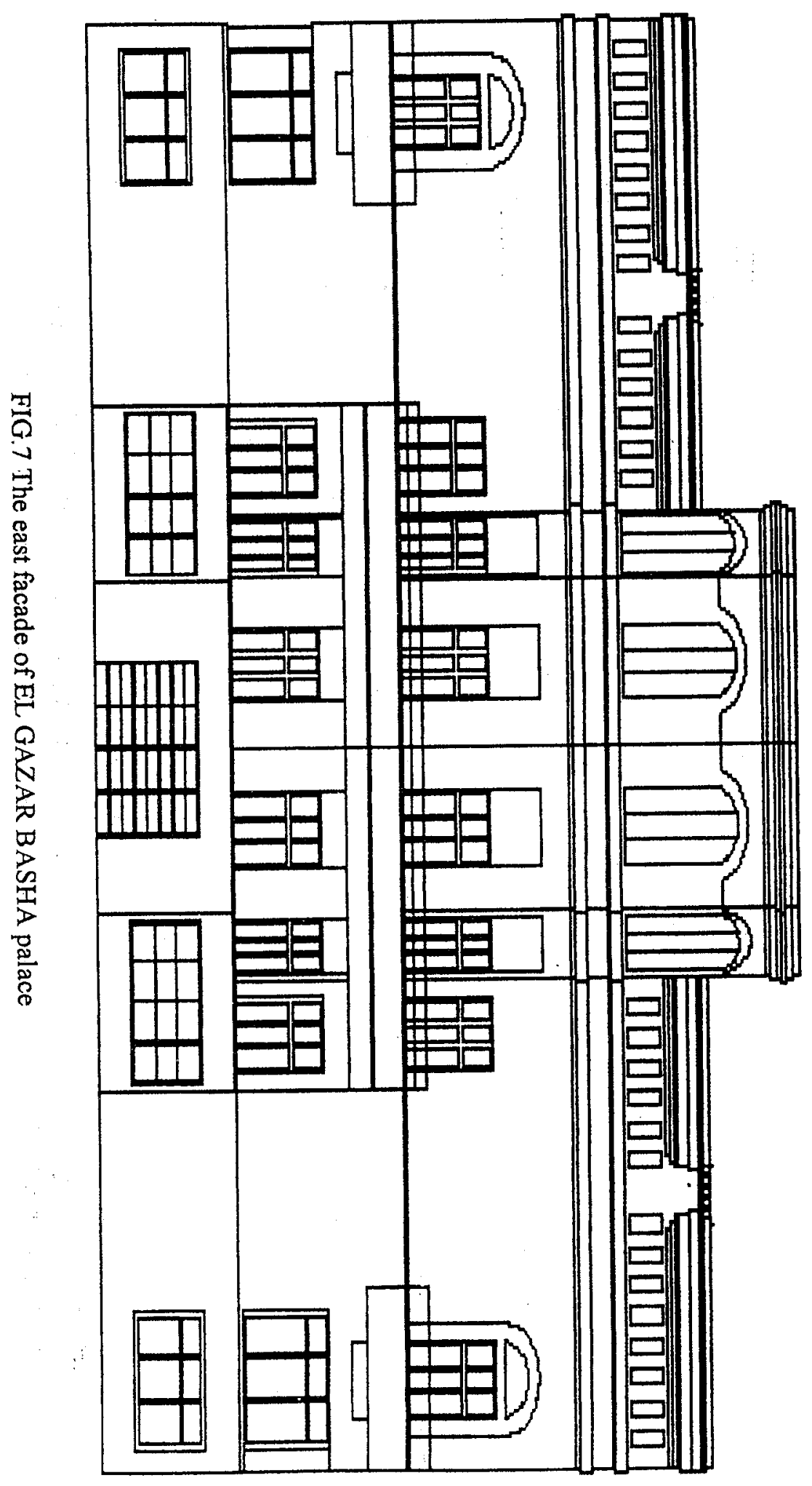


DISCUSSION OF THE OBTAINED RESULTS

TABLE 2. THE COMPARISON BETWEEN THE TOTAL STATION SURVEY AND THE ANALYTICAL PHOTOGRAMMETRY

\begin{tabular}{|c|c|c|}
\hline$\overline{\text { ITEM }}$ & TOTAL STATION & $\begin{array}{c}\text { ANALYTICAL } \\
\text { PHOTOGRAMMETRY }\end{array}$ \\
\hline $\begin{array}{l}\text { Number of necessary } \\
\text { point to represent the } \\
\text { two facades }\end{array}$ & 1388 pts. & 1388 pts. \\
\hline $\begin{array}{l}\text { Time need to drawing } \\
\text { the two facades }\end{array}$ & $04^{\mathrm{h}} 30^{\mathrm{m}} \quad 00^{\mathrm{s}}$ & $04^{\mathrm{h}} \quad 30^{\mathrm{m}} \quad 00^{\mathrm{s}}$ \\
\hline $\begin{array}{l}\text { Time need to get the } \\
\text { object space coordinates }\end{array}$ & $12^{\mathrm{h}} \quad 30^{\mathrm{m}} \quad 00^{\mathrm{s}}$ & $32^{\mathrm{h}} \quad 20^{\mathrm{m}} \quad 00^{\mathrm{s}}$ \\
\hline Material needed & No need & $\begin{array}{l}\text { Films- Developing- Fixing- } \\
\text { water-drying }\end{array}$ \\
\hline Auxiliary Instruments & No need & $\begin{array}{l}\text { Theodolite, Comparator } \\
\text { mono or stereo) }\end{array}$ \\
\hline $\begin{array}{ll}\text { Extra } & \text { program } \\
\text { requirement } & \end{array}$ & No extra program & Bundle adjustment \\
\hline $\begin{array}{l}\text { Control points or } \\
\text { control distances }\end{array}$ & $\begin{array}{l}\text { One control point for } \\
\text { each facade }\end{array}$ & $\begin{array}{l}\text { Minimum } 3 \text { control points } \\
\text { for each facade } \\
\text { and/ or control distances }\end{array}$ \\
\hline Geodetic observations & $\begin{array}{c}\text { local coordinate } \\
\text { system }\end{array}$ & local coordinate system \\
\hline $\begin{array}{l}\text { Accuracy in term of } \\
\text { RMS of coordinate } \\
\text { differences }\end{array}$ & $2-7_{\mathrm{mm}}$ & $2-10_{\mathrm{mm}}$ \\
\hline Beloning's group & 2nd group & 2nd group \\
\hline The output form & $\begin{array}{l}\text { Only map sheet } \\
\text { to scale }\end{array}$ & $\begin{array}{l}\text { Archieve Film (negative } \\
\text { and positive)and MAP } \\
\text { sheet to scale }\end{array}$ \\
\hline
\end{tabular}

TABLE (3) : STATISTICS OF OBTAINED COORDINATE DIFFERENCES BETWEEN BOTH ANALYTICAL PHOTOGRAMMETRY AND TOTAL STATION TECHNIQUES AT THE USE CHECK POINTS

\begin{tabular}{|c|c|c|c|c|c|c|}
\hline $\mathrm{Pt}$. & \multicolumn{3}{|c|}{ Total Station } & \multicolumn{3}{|c|}{ Analytical Photogrammetry } \\
\hline & $\Delta \mathrm{X}$ & $\Delta \mathrm{Y}$ & $\Delta Z$ & $\Delta \mathrm{X}$ & $\Delta \mathrm{Y}$ & $\Delta Z$ \\
\hline 1 & 1.13 & 1.51 & 1.16 & 1.38 & 2.9 & 2.15 \\
\hline 2 & 1.31 & 1.43 & 1.28 & 1.48 & 1.73 & 1.48 \\
\hline 3 & 1.41 & 1.82 & 1.6 & 1.2 & 1.63 & 1.24 \\
\hline 4 & 0.98 & 1.37 & 1.01 & 1.43 & 1.85 & 1.48 \\
\hline 5 & 1.1 & 1.54 & $1 . \overline{36}$ & 1.24 & 2.54 & 1.39 \\
\hline 6 & 2.01 & 1.71 & 1.71 & 2.35 & 1.75 & 1.98 \\
\hline 7 & 1.02 & 1.03 & 1.21 & 1.29 & 1.58 & 2.23 \\
\hline 8 & 1.01 & 1.31 & 1.26 & 2.55 & 1.87 & 1.34 \\
\hline 9 & 1.2 & 1.47 & 1.31 & 1.39 & 1.54 & 1.44 \\
\hline 10 & 1.3 & 1.39 & 1.1 & 1.38 & 1.81 & 1.52 \\
\hline \multicolumn{3}{|c|}{ RMS } & \multicolumn{2}{|c|}{ Total Station } & \multicolumn{2}{|c|}{$\begin{array}{c}\text { Analytical } \\
\text { Photogrammetry }\end{array}$} \\
\hline \multicolumn{3}{|c|}{ RMS(Maximum) } & \multicolumn{2}{|c|}{2} & \multicolumn{2}{|c|}{2} \\
\hline \multicolumn{3}{|c|}{ RMS(Minimum) } & \multicolumn{2}{|c|}{7} & \multicolumn{2}{|c|}{10} \\
\hline
\end{tabular}


The coordinates which are computed from the total station survey and analytical photogrammetry are compared by the RMS-values of the coordinate differences in the check points. The comparison of results is shown in table (2) and table (3).

Regarding to the comparison between the total station survey and analytical photogrammetry, the following remarks can be stated :

-The obtained accuracy from the total station survey was found comparable with the corresponding accuracy obtained from the close- range photogrammetric results.

-In analytical photogrammetry, the instruments which are required for the photography and for measuring the image coordinates are very expensive by comparison with the total station.

-The accuracy of the analytical photogrammetry depends on the lay out of the two camera stations, number of stations, density of control points, the precision of the measured image coordinates and the focal length of the camera, but the accuracy of the total station depends on only the instrument and the operator .

-In analytical photogrammetry, one cannot reach the required accuracy for measuring the image coordinates by using small scale; and to overcome the scale problem in analytical photogrammetry, specially in the narrow streets ,the photographs can be taken from the ground, from scaffolding, from the roofs of neighboring buildings, or from a platform mounted on an elevating system and this means more budget more time and great effort, but in the total station, there is no limitations on the format size and intensity of light. -In analytical photogrammetry, one often encounters some difficults, such difficults may be due to large depths of field compared with the average object distance and to the fact that, the image of the object covers only a part of the photograph, in the total station survey, there are no problem with the depth of field and the overlaps ( minimum distance by the 3SET is $1.5 \mathrm{~m}$ and maximum distance is $2000 \mathrm{~ms}$ ).

-The photographs contain a wealth of interpretable information; thus one can say that, the photogrammetric archives of the building assume an "intellectual conservation" of the building in its "effective shape", at a precise moment in its history, but The total station survey takes no account of perspective, but simply shows details and parts geometrically.

-The photographs are lasting documents from which, measurements can be derived at any time in the future; thus in case of the total station survey, sufficient measurements must be taken in the field to enable the whole to be draw out in the office. It can be most inconvenient and costly if further visits to the site have to be made, because important dimensions have been missed

-In case of the analytical photogrammetry, one need time to reconnaissence ; to plane the project and to determine the lay out of the camera stations, but in case of the total station survey, one needs only to reconnaissence the site. -In both cases it is also very important to know how measurements are noted down, to enable the plotting process to be carried out successfully .

-The total station reduce the required time by about $50 \%$ in comparison with the analytical photogrammetry. 
-The profitability of the total station survey is the higher, and the greater number of points to be measured.

-The total station can be used in any type of preliminary survey, control survey or layout survey beside in the architectural photogrammetry .

From the above discussions, one can say that by using the total station in architectur photogrammetry, not only working times saved, but also money for wages and materials. Therefore, one can advise to use the total station in architectural photogrammetry.

\section{CONCLUSIONS}

The test site has been successfully used for the comparison between the total station survey and the analytical photogrammetry in architectural photogrammetry .The presnted example show the feasiblty of the total station in architectural photogrammetry. The practical experiment has proved that the total station survey is considerably more simple, rapid and economic than using the close range photogrammetric technique. Moreover, the obtained accuracy from the total station survey was found comparable with the corresponding accuracy obtained from the close range photogrammetric results, therefor one can suggest to use the total station in architectural photogrammetry as a low - cost system.

\section{REFERENCES}

[1] Abdel- Gawad, A.K. (1994) “ The Application of High precise Surveying Tecnique in Measuring Deformations of Structures" M.Sc. Thesis,Faculty of Engineering,Ain Shams University

[2] Behairy, A. M. and Zahran, M.I.,(1990) "Reliability for Close Range Photogrammetry " Proceeding of the First Conference on Civil Eng., Volume 2, Military Technical College.

[3] Carbonnel,M. and Dallas,R.W.,1985 The International Committee for Architectural Photogrammetry (CIPA) Aims,Achievements,Activities.Photogrammetria, 40(2): 193-202.

[4] Ebner, Fristsch and Heipke 1991 Digital photogrammetric systems Wichmann verlag

[5] Karara ,H.,M. 1989 Non - topographic photogrammetry American Society for photogrammetry and remote sensing.

[6] Rahil,A.M. (1997) "A Comparative Study of Different Configuration Systems in Cose-Range Photogrammetry" Civil Engineering Research Magazine EL-AZhar Univ., Vol.(19),No.5,1997

[7] Von Gelder, B.H., 1994, " Geodetic Control Survey: Lecture Notes ", Purdue University, Civil Eng. Dep.,West Lafayette, IN., USA

[8]Wester-Ebbinghause,W.,1980 Numerische Verfahren fur die Architekturphotogrammetrie. International Archives of photogrammetry, XXIII (B5):813-823. 
بحطات الرصد المتكاملة وإستخلامها فل أعمال التسجيل والرفع المعمارى الفوتوبر امترى

$$
\text { د. أبو الحسن محمد رحميل }
$$

كلية المندسة-قسم المندسة المدنية-جامعة المنوفية-شيين الكوم

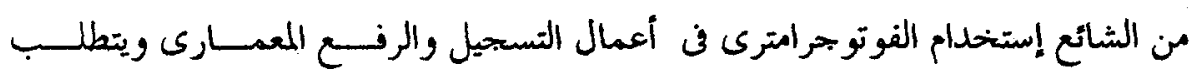


وأحهزة بتسيم الصور وأجهزة القياس على الصور كماتكون هناك حاجة إلى إســـتخدام

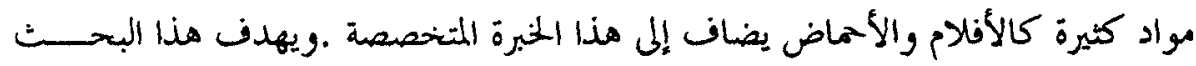
إلى دراسة إمكاتية إستخدام محطات الرصد المتكاملة (Total station) في أعمال التسجيل

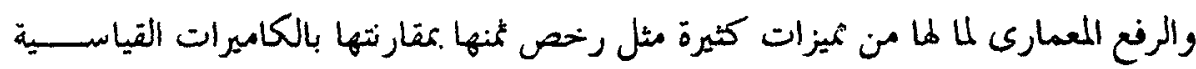

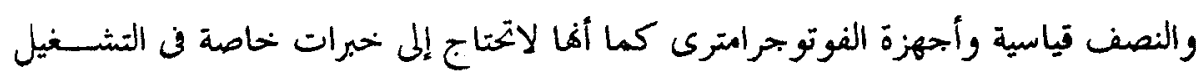

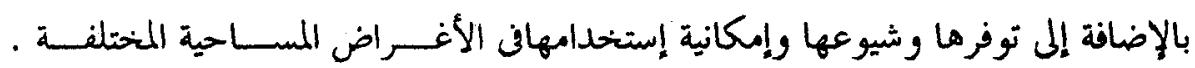

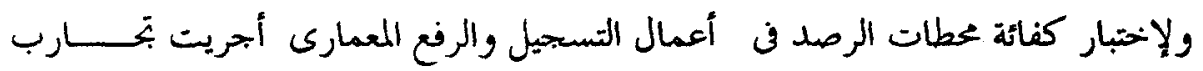
على قصر الجزار باشا بإدارة جامعة المنوفية بمدينة شبين الكوم بإعتبارة أحد المعالم الأثريسـة

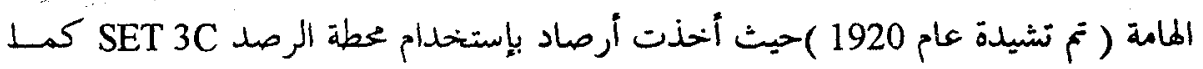

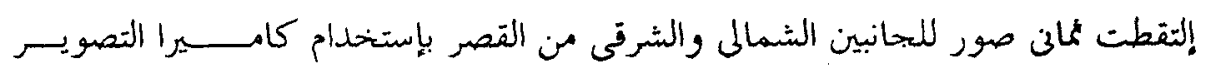


عمل مقارنة بين نتائج محطة الرصد والفوتوجرامترى التحليلى من حيث الوقت المستغرق

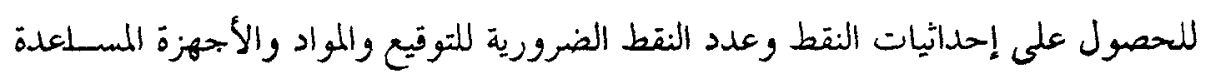



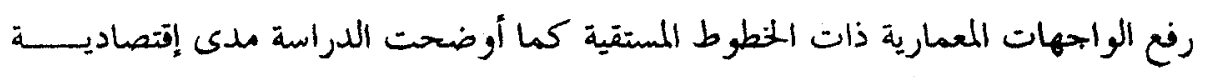
محطات الرصد من حيث رخص سعرما مقارنة بالكاميرات القياسية والغير قياسية كما أن

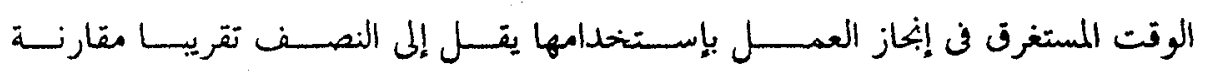

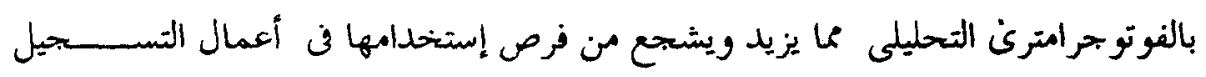

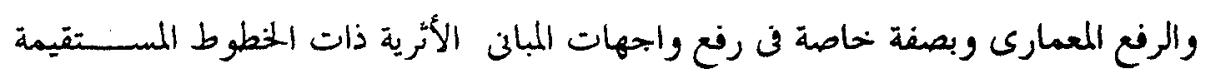

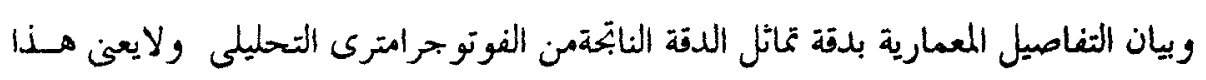

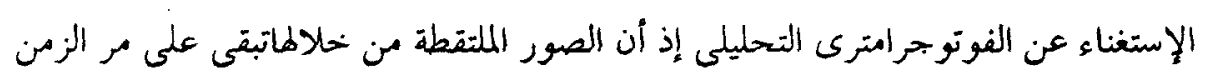

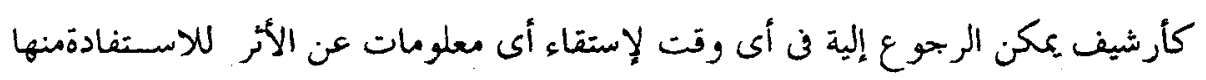

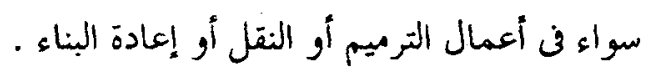

